ARTIGO

Recebido em: $12 / 05 / 2017$

Aceito em: $01 / 12 / 2017$

\title{
Técnicas de análise de dados empregadas no Programa de Pós-graduação de Ciência da Inf ormação da Universidade Estadual de Londrina
}

\author{
Data analisys techniques used in the Information Science Postgraduate \\ Program of Londrina State University
}

\author{
Rosemari Pereira dos Santos ALVES (rosebiblio@hotmail.com)* \\ Sueli BORTOLIN (suelibortolin@gmailcom)** \\ Adriana Rosecler ALCARÁ (adrianaalcara@gmailcom)** \\ * Mestranda do Programa de Pós-Graduação em Ciência da Informação - UEL. \\ ** Professora do Departamento de Ciência da Informação - UEL.
}

Resumo: A metodologia da pesquisa constitui um dos elementos que confere aos estudos investigativos rigorosidade e reconhecimento perante a ciência. Diante disso, o objetivo deste artigo foi investigar quais os procedimentos de análise de dados usados nas dissertações do Programa de Pós-Graduação de Ciência da Informação da Universidade Estadual de Londrina e aferir, nestas, a frequência do emprego da análise de conteúdo. Para tanto, foi realizada uma pesquisa documental indireta, de cunho bibliográfico, recuperando 28 dissertações, defendidas nos anos de 2014 e 2015, e sintetizando o conteúdo daquelas que utilizaram a análise de conteúdo. Entre os resultados verificou-se que a análise de conteúdo foi uma das técnicas mais empregadas nas pesquisas deste Programa.

Palavras-chave: Metodologia da pesquisa; Técnicas de análise de dados; Análise de conteúdo.

\begin{abstract}
Research methodology constitutes one of the elements which bestows, to investigative studies, rigorousness and acknowledgement before Science. Thus, this paper intends to investigate what procedures of data analysis are used in the dissertations of the Information Science Postgraduate Program of Londrina State University, measuring the frequency of the adoption of content analysis. In order to fulfill this objective, an indirect bibliographic documental research was conducted, retrieving 28 dissertations, from 2014 and 2015, and synthesizing the contents of those that used the content analysis. Among the results it was verified that content analysis was one of the most used techniques in the researches of this Program.
\end{abstract}

Keywords: Research Methodology; Data analysis techniques; Content analysis.
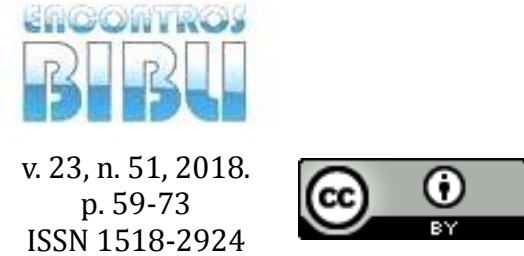


\section{INTRODUÇÃO}

A produção científica é responsável pela construção e solidificação de novos conhecimentos, continuidade das investigações e evolução de determinado campo, além de colaborar para o desenvolvimento científico e tecnológico de um país. Juntamente com o avanço tecnológico, que tem contribuído para que a ciência seja amplamente divulgada e expandida, as Instituições de Ensino Superior, a partir dos cursos de pós-graduação (mestrado e doutorado), vem ao longo do tempo formando pesquisadores para contribuir com a propagação e a utilização do conhecimento.

A metodologia da pesquisa, na produção científica, constitui um dos elementos que confere aos estudos investigativos rigorosidade e reconhecimento perante o estatuto de Ciência. Seu uso perfaz um importante instrumento de caracterização de uma investigação, dando-lhe a correta forma mediante a qual se empregam métodos e técnicas que são adotados para a obtenção do conhecimento acerca do objeto de estudo. Logo, seu emprego possibilita buscar a solução de um problema estabelecido, testar uma hipótese, bem como fazer cumprir objetivos que se constituem na produção de determinado conhecimento.

Dada a amplitude de tal conjectura é necessário buscar a melhor forma de se escolher métodos adequados e eficientes para o desenvolvimento racional de uma pesquisa, pois a escolha impacta sobremaneira na análise dos dados científicos. Outro ponto a se considerar é que tal escolha deve, necessariamente, estar intrinsecamente ligada aos objetivos estabelecidos, já que uma escolha errada, em termos de métodos, compromete todo um trabalho e perde o rigor metodológico imprescindível a qualquer trabalho de natureza científica (POPPER, 1993). Marconi e Lakatos (2010) entendem que o uso dos métodos é de certa forma uma prerrogativa da ciência. Em termos específicos, o método é entendido como um conjunto de atividades racionais e sistemáticas que possibilitam alcançar o objetivo de modo seguro e sem esforços desnecessários.

Nesse sentido, este trabalho tem como objetivo investigar quais foram os procedimentos de análise de dados usados nas dissertações do Programa de Pósgraduação de Ciência da Informação da Universidade Estadual de Londrina (PPGCI/UEL) e aferir a frequência do emprego da análise de conteúdo. Para tanto, foi realizada uma pesquisa documental indireta, de cunho bibliográfico, que recuperou 28 dissertações, defendidas nos anos de 2014 e 2015. Em seguida, foi realizada uma síntese das dissertações que utilizaram a técnica de análise de conteúdo. 0 artigo se justifica por evidenciar à comunidade cientifica o emprego desta técnica, explanando seu conceito e identificando como tem sido aplicada neste Programa.

Quanto à estrutura deste artigo, na primeira parte é apresentado o referencial teórico, o conceito de análise de conteúdo, principalmente com base na obra de Laurence Bardin. Na segunda parte, é mostrado o levantamento de todas as dissertações com seus respectivos procedimentos de análise, visando a incidência do percentual de adoção de análise de conteúdo para determinar sua frequência e, enfim, sintetizar os trabalhos que adotam a técnica em questão, para determinar em que tipo de pesquisa ela tem sido empregada.

\section{REFERENCIAL TEÓRICO}

A Análise de Conteúdo (AC) é um conjunto de técnicas. Segundo Marconi e Lakatos (2002), técnicas de pesquisa são preceitos e processos que servem uma ciência ou arte na obtenção de seus propósitos. Conforme Bardin (2011), a AC utiliza procedimentos sistemáticos e objetivos para obter indicadores que permitam a inferência de conhecimentos relativos às variáveis inferidas da mensagem. Ela possui 
três fases: a pré-análise, a exploração do material e o tratamento dos resultados inferência e interpretação (sendo importante destacar que as duas primeiras fases constituem a etapa descritiva da análise), que serão detalhadas mais adiante.

As técnicas que compõem esse conjunto são: análise categorial, análise de avaliação, análise da enunciação, análise da expressão, análise das relações e análise do discurso (BARDIN, 2011). Apesar disso, é comum que autores se refiram à análise de conteúdo simplesmente como um "método".

A análise de conteúdo é uma técnica de pesquisa que trabalha com a palavra, permitindo de forma prática e objetiva produzir inferências do conteúdo da comunicação de um texto replicáveis ao seu contexto social Nela o texto é um meio de expressão do sujeito, onde o analista busca categorizar as unidades de texto (palavras ou frases) que se repetem, inferindo uma expressão que as representem. Conforme Godoy (1995), na sua origem a análise de conteúdo tem privilegiado as formas de comunicação oral e escrita, o que não deve excluir outros meios de comunicação. Qualquer comunicação que vincule um conjunto de significações de um emissor para um receptor pode, em princípio, ser traduzida por esta técnica.

De acordo com a definição, a intenção da análise de conteúdo é obter indicadores para se fazer inferências. Bardin (2011) ensina que os indicadores são índices fornecidos pela etapa descritiva da análise, cumprindo o papel de vestígios com os quais o analista pode trabalhar, assim como os sintomas cumprem o mesmo papel para o trabalho dos médicos. Woida (2010) esclarece que os indicadores podem revelar aspectos implícitos do conteúdo analisado. As inferências, por sua vez, são deduções lógicas que explicam os antecedentes e as consequências da mensagem analisada. Bardin (2011) explica que a inferência se situa entre a descrição e a interpretação da mensagem, em uma etapa intermediária.

As variáveis inferidas da mensagem, termo final da definição, consistem no objeto da análise de conteúdo. Por intuição seria razoável esperar que o objeto da análise fosse a própria palavra, porém tal posição é ocupada pelo campo das determinações da mensagem, ou seja, pelas condições de sua produção. Bardin (2011) critica essa denominação (condições de produção) pelo fato de ela excluir as condições de recepção, que também estão contidas no objeto. Portanto, ela prefere a expressão "variável inferida", que possui uma conotação mais neutra. Woida (2010) sintetiza que o ponto central do método é a descrição do conteúdo de um texto levando em conta a construção de indicadores para realizar inferências. Portanto, trata-se de um processo de descrever, inferir e interpretar.

Como mencionado, o conjunto de técnicas em questão possui três fases para sua utilização. A primeira delas é a pré-análise, na qual as ideias iniciais são sistematizadas. Segundo Bardin (2011), essa fase possui três missões: $1^{a}$ ) escolha do material a ser submetido à análise; $2^{\underline{a}}$ ) formulação das hipóteses e objetivos; $3^{\underline{a}}$ ) elaboração de indicadores. Trata-se de uma fase com procedimento informal e intuitivo, podendo ser impossível cumprir as missões em ordem cronológica, visto que os fatores são interdependentes.

A escolha do material é uma atividade que culmina na constituição de um corpus. Bardin (2011) define corpus como o conjunto de documentos a serem submetidos à análise. Sua construção segue algumas regras, das quais se destacam: a exaustividade, que impede que documentos elencados deixem de ser analisados, devendo-se esgotar a totalidade das comunicações que serão utilizadas; a representatividade, que exige que a amostra abranja todo o universo representado, a fim de que os resultados da análise sejam generalizáveis; a exclusividade, que impede que um mesmo elemento seja classificado em mais de uma categoria; a homogeneidade, que exige que os documentos sejam escolhidos com base em 
critérios preestabelecidos, impedindo a inclusão arbitrária de materiais e garantindo a consistência do corpus; e a pertinência, que exige que os documentos sejam adequados ao objetivo da análise.

Enquanto os materiais são adicionados ao corpus, eles devem ser submetidos a uma leitura flutuante (BARDIN, 2011). Trata-se de leitura livre com o intuito de conhecer o conteúdo do documento. Se, após a leitura, for decidido que o documento deve permanecer no corpus, passa a ser possível formular, a partir dele, hipóteses e objetivos. Bardin (2011) entende que hipóteses são afirmações provisórias que se pretende confirmar ou infirmar por meio da análise. Objetivos, seguindo o entendimento, são as finalidades gerais da análise, em prol das quais os resultados obtidos seriam usados.

Enfim, a elaboração de indicadores fornece as ferramentas que viabilizam a interpretação. Os indicadores são fixados com base nos materiais selecionados e nas hipóteses e objetivos estabelecidos. No entanto, eles podem acabar inspirando novas hipóteses e objetivos, bem como sugerindo novos documentos para integrar o corpus. Esse caráter espontâneo da pré-análise, por meio do qual são criados e alterados planos durante a execução, decorre da interdependência anteriormente mencionada. A missão do pesquisar nessa fase começa com índices provisórios que vão se definindo ao longo da fase, até se tornarem indicadores precisos e seguros. Ao final da fase, é importante realizar o pré-teste de análise dos indicadores, ou seja, testar sua eficácia e pertinência para que as etapas posteriores tenham um fundamento sólido para se desenvolverem (BARDIN, 2011). Antes de encerrar a pré-análise, esta autora lembra como é indispensável fazer a preparação do material Trata-se de um procedimento formal de organização e padronização dos documentos selecionados. Ela engloba desde a transcrição de entrevistas até a classificação de textos.

Finda a primeira fase da análise de conteúdo, procede-se para a fase de exploração do material, que é a mais mecânica de todo o processo. Sua missão consiste em codificar e categorizar os dados brutos analisados, em conformidade com o que foi estipulado na pré-análise (BARDIN, 2011). 0 procedimento começa com o recorte do texto, para identificar os elementos a serem analisados, que podem servir como unidade de registro ou de contexto. As unidades de registro são os elementos básicos da análise, podendo ser palavras, temas, eventos etc, dependendo da técnica aplicada. A unidade de contexto é no ambiente no qual a unidade de registro está inserida, ou seja, consiste em um recorte ao redor desta (com dimensões fixadas em função da pertinência) necessária para a compreensão de sua significação exata (BARDIN, 2011).

A partir do recorte, é possível enumerar os elementos, contar suas frequências e constatar, com base em referência, sua presença ou ausência. A enumeração é orientada por uma regra, que pode atribuir pesos para unidades de registro e alterar seus valores de acordo com sua intensidade (que pode ser observada, por exemplo, em advérbios, quando se trata de texto), entre outros recursos de avaliação (BARDIN, 2011). Para ilustrar esse procedimento, no caso da ponderação com base na intensidade dos elementos, ao se medir a frequência de palavras que expressam desaprovação, em entrevistas sobre a Reforma Previdenciária, termos como "injusto" e "absurdo" possuem um valor que pode ser amplificado por advérbios como "muito" e "demais". Assim, enquanto se conta 1 ponto para "injusto", pode-se contar 2 ou mais pontos para "injusto demais".

Vale destacar que o recorte e a enumeração representam atividades de codificação, o procedimento seguinte é de natureza taxonômica. Trata-se da categorização, que se inicia com o inventário, etapa que isola os elementos codificados, e prossegue com a classificação, que consiste em sua organização de 
acordo com categorias. Bardin (2011) adverte que boas categorias devem seguir condições de ser: mutuamente exclusivas, com cada elemento sendo mapeado para apenas uma categoria, como uma função, na matemática, que só é válida se para cada valor de entrada há um único valor de saída; homogêneas, obedecendo, todas elas, aos mesmos princípios de classificação; pertinentes, se adequando às hipóteses e objetivos preestabelecidos; objetivas, superando a tendência do classificador de emitir juízos subjetivos; e produtiva, devendo possuir o potencial para fornecer resultados.

Após a exploração do material, procede-se para a terceira fase da análise de conteúdo, que é a de tratamento dos resultados em que se faz a inferência e a interpretação. Nessa etapa, conforme Bardin (2011), os resultados brutos obtidos são transformados em informações significativas e válidas que podem ser representadas em tabelas e diagramas. Nesse momento, surge a possibilidade de se propor inferências e dar início ao trabalho interpretativo. A inferência, como já foi dito, busca explicar os antecedentes e consequentes do conteúdo analisado, ou seja, conforme Bardin (2011), entender as causas (variável inferida) a partir dos efeitos (variável de inferência, ou seja, indicador).

Dois tipos de inferências se apresentam para realizar essa função: a específica e a geral. A inferência específica é usada para responder uma pergunta pontual, trabalhando, assim, com uma variável inferida não generalizável. Ao contrário, a inferência geral procura estabelecer causas gerais, que se relacionem não apenas com um caso especial. Bardin (2011) explica que, para transcender a esfera das inferências específicas, é preciso rever os índices e inferências de análises anteriores, bem como a situação da comunicação, fazendo, de certa maneira, uma análise de conteúdo que tem como objeto outra análise de conteúdo.

A partir das inferências, são realizadas as interpretações. Conforme Lima e Manini (2016), trata-se da atividade com a qual o pesquisador alcança os objetivos propostos pela AC. Ela consiste em expressar os elementos necessários para elucidar o objeto de estudo e as hipóteses, exigindo do analista criatividade e diligência.

Finda a terceira fase, encerra-se a aplicação desta técnica, sendo possível fazer uso dos resultados para fins teóricos, pragmáticos ou como fundamento para uma nova análise (BARDIN, 2011). Trata-se, portanto, de um método objetivo e sistemático que tanto serve como fonte para justificar argumentos científicos quanto para base de novas análises, que podem deixar os resultados cada vez mais refinados.

É importante observar que a análise de conteúdo é um método muito versátil, podendo ser aplicado em diversas áreas do conhecimento. Enquanto Bardin trabalha no campo da Psicologia, deixando evidente a utilidade do método na saúde, o caráter lógico-semântico da análise de conteúdo, que, de acordo com Woida (2010), consiste na preocupação tanto da lógica para categorização quanto da semântica para entender o significado das unidades de registro, permite sua aplicação nas Ciências Humanas e, até mesmo, nas Exatas. No entanto, sua maior afinidade está na área da Comunicação, o que é confessado na definição de Bardin, estudada no início do referencial teórico.

Tendo em mente esse trânsito por diversas áreas do conhecimento, percebese a importância de se conhecer a história do método. Os antecedentes da análise de conteúdo consistem em diversas práticas que envolviam processos hermenêuticos. Tais práticas englobam desde a interpretação de sonhos até a lógica e a retórica (BARDIN, 2011). A primeira prática conhecida com maior rigor metodológico, e que, portanto, se aproxima mais da análise de conteúdo propriamente dita, foi uma pesquisa sueca sobre hinos religiosos luteranos, de 1640, que analisava seus temas, valores, modalidades de aparição e complexidade estilística. 
Bardin (2011) relata que a história passa dos antecedentes para a própria análise de conteúdo no começo do século XX, especialmente devido ao trabalho desenvolvido pela Escola de Jornalismo de Colúmbia, nos Estados Unidos. Na época, o foco da aplicação da técnica era em estudos quantitativos, como confirma Woida (2010).

O marco desse período histórico foi, em 1927, a publicação do livro Propaganda Technique in World War I, de Harold D. Lasswell, um dos pioneiros no estudo da análise de conteúdo. Lasswell (2010) discutiu como classificar o conteúdo da propaganda e sumarizar os procedimentos de organização e condução das campanhas propagandísticas. Realizou, assim, uma análise categorial extremamente importante tanto para as comunicações sociais, devido ao conteúdo trabalhado, quanto para a metodologia científica, pelo método empregado e pela discussão metodológica de como empregá-lo.

De acordo com Bardin (2011), além das Comunicações Sociais, outra área muito importante para o desenvolvimento da análise de conteúdo foi a Psicologia, especialmente o behaviorismo, que prefere trabalhar com técnicas objetivas ao invés de introspecções intuitivas. Com o término da Segunda Guerra Mundial, foi a Ciência Política que assumiu papel de destaque no desenvolvimento da análise de conteúdo. Bardin (2011) afirma que 25\% dos estudos que empregavam o método eram investigações políticas. Desde então, muitos cientistas começaram a se especializar neste método. 0 outro evento de significância para este assunto foi a definição do método por Berelson, segundo o qual "a análise de conteúdo é uma técnica de investigação que tem por finalidade a descrição objetiva, sistemática e quantitativa do conteúdo manifesto da comunicação" (1948 apud BARDIN, 2011, p.19).

Após esta fase, a análise de conteúdo passou por um período de desengano, provavelmente por ter sido superestimada e, eventualmente, revelado suas limitações. Graças ao estudo da psicolinguística, no entanto, o método voltou a receber atenção, ganhando, até mesmo, uma dimensão qualitativa. 0 retorno pelo interesse por esta técnica coincidiu com o desenvolvimento dos computadores, fenômeno de importância devido ao recurso do ordenador. Bardin (2011) explica que ordenadores são programas capazes de executar qualquer tarefa que possa ser expressa pelo analista com instruções livres de ambiguidade. 0 uso de ordenadores permite "digerir" rapidamente quantidades astronômicas de dados, que seriam impossíveis de se tratar manualmente. Portanto, trata-se de um recurso que vem otimizando a aplicação do método.

Conforme já foi mencionado, a análise de conteúdo apresenta-se como uma técnica bastante variável, sendo que as três fases apresentadas (pré-análise, exploração do material e tratamento do resultado) podem ser conduzidas de diferentes formas, dependendo do objeto e unidades de análise.

\section{PROCEDIMENTOS METODOLÓGICOS}

Para atender ao objetivo desta pesquisa foi realizada uma pesquisa documental indireta, de cunho bibliográfico, com abordagem quantiqualitativa. Para tanto, inicialmente foram identificadas, por meio da Biblioteca Digital de Teses e Dissertações da UEL, as dissertações defendidas no PPGCI/UEL nos anos de 2014 a 2015.

Foram localizadas 28 dissertações, que se constituíram no corpus desta pesquisa. Por meio da leitura do resumo e do capítulo destinado aos procedimentos metodológicos, identificou-se os delineamentos e técnicas de coleta e análise de dados adotados e em seguida construiu-se um quadro relacionando os resultados. Em 
seguida, com base no referencial teórico, selecionou-se todas as dissertações que empregaram a análise de conteúdo ou técnicas que pertencem ao conjunto e, por meio da leitura das dissertações, realizou-se uma síntese de cada pesquisa, destacando o objetivo e como a análise de conteúdo foi empregada.

A princípio, esperava-se que a simples leitura do resumo ou dos procedimentos metodológicos fosse o suficiente para se determinar, com segurança, quais delineamentos e técnicas foram adotadas, no entanto, em muitos casos, fez-se necessário buscar tais informações em outros capítulos das dissertações analisadas. Isso indica um descuido na maneira como a redação dos procedimentos metodológicos está sendo tratada. É necessário detalhar a metodologia com clareza e que os métodos empregados sejam declarados com exatidão, no entanto muitas redações anunciam as técnicas escolhidas com timidez e as definem de maneira ambígua.

\section{RESULTADOS}

Para obter o título de mestre é preciso desenvolver uma dissertação para defender uma ideia, o que exige uma rigorosa investigação cientifica sobre o tema da pesquisa por parte do mestrando. Sendo assim, as dissertações contribuem significativamente para o crescimento e fortalecimento da comunicação científica, servindo como fonte de pesquisa para futuros trabalhos acadêmicos.

Por meio do quadro 1, é possível observar que, em 2014, ano em que o PPGCI/UEL teve sua primeira turma de defesas de dissertações no Programa de Mestrado Acadêmico, o número de dissertações apresentadas foram 13 e no ano seguinte 15, totalizando 28 dissertações.

\begin{tabular}{|c|c|c|c|}
\hline Índice & Título da Dissertação & $\begin{array}{c}\text { Delineamentos e Técnicas } \\
\text { Adotadas }\end{array}$ & Ano \\
\hline 1 & $\begin{array}{l}\text { A abordagem da análise de domínio na } \\
\text { organização e representação do } \\
\text { conhecimento em arquivística }\end{array}$ & $\begin{array}{l}\text { Pesquisa bibliográfica e } \\
\text { documental; } \\
\text { Análise de Domínio. }\end{array}$ & 2014 \\
\hline 2 & $\begin{array}{l}\text { A aplicação do modelo RDF na descrição } \\
\text { arquivística: em foco a Norma } \operatorname{ISAD}(G)\end{array}$ & $\begin{array}{l}\text { Pesquisa bibliográfica e } \\
\text { documental; } \\
\text { Análise documental (Técnica } \\
\text { de Modelagem Unified } \\
\text { Modeling Language). }\end{array}$ & 2014 \\
\hline 3 & $\begin{array}{l}\text { A interdisciplinaridade na Ciência da } \\
\text { Informação: } \\
\text { bibliométricas }\end{array}$ & Análise Bibliométrica. & 2014 \\
\hline 4 & $\begin{array}{l}\text { A representação temática da informação } \\
\text { na saúde coletiva: tendências temáticas } \\
\text { dos trabalhos desenvolvidos pelo } \\
\text { programa de pós-graduação da } \\
\text { Universidade Estadual de Londrina }\end{array}$ & $\begin{array}{l}\text { Pesquisa bibliográfica e } \\
\text { documental; } \\
\text { Análise de Assunto. }\end{array}$ & 2014 \\
\hline 5 & $\begin{array}{l}\text { A topografia da dark web e seus não } \\
\text { lugares: por um estudo das dobras } \\
\text { invisíveis do ciberespaço }\end{array}$ & $\begin{array}{l}\text { Pesquisa bibliográfica e } \\
\text { documental; } \\
\text { Método indutivo informal e } \\
\text { dedutivo formal; } \\
\text { Análise documental. }\end{array}$ & 2014 \\
\hline 6 & $\begin{array}{l}\text { Compartilhamento da informação e do } \\
\text { conhecimento na rede dos } \\
\text { coordenadores dos Programas de Pós- } \\
\text { Graduação em Ciência da Informação }\end{array}$ & $\begin{array}{l}\text { Formulário e questionário; } \\
\text { Análise de Redes Sociais } \\
\text { (ARS); } \\
\text { Análise documental }\end{array}$ & 2014 \\
\hline
\end{tabular}




\begin{tabular}{|c|c|c|c|}
\hline 7 & $\begin{array}{l}\text { Comportamento Informacional de pais } \\
\text { de crianças com Síndrome de Down }\end{array}$ & $\begin{array}{l}\text { Pesquisa documental; } \\
\text { Análise de conteúdo. }\end{array}$ & 2014 \\
\hline 8 & $\begin{array}{l}\text { Desenvolvimento e formação de } \\
\text { competência em informação: um } \\
\text { mapeamento de modelos, padrões e } \\
\text { documentos }\end{array}$ & $\begin{array}{l}\text { Pesquisa bibliográfica e } \\
\text { documental; } \\
\text { Análise documental, com } \\
\text { representação dos } \\
\text { documentos por meio de } \\
\text { mapa conceitual }\end{array}$ & 2014 \\
\hline 9 & $\begin{array}{l}\text { O negro e a mediação: a ciência da } \\
\text { informação como campo de discussão } \\
\text { étnico-racial }\end{array}$ & $\begin{array}{l}\text { Pesquisa bibliográfica e } \\
\text { documental; } \\
\text { Análise produção cientifica; } \\
\text { Análise de documento }\end{array}$ & 2014 \\
\hline 10 & $\begin{array}{l}\text { Organização da informação em sites de } \\
\text { televisões de universidades públicas } \\
\text { brasileiras }\end{array}$ & $\begin{array}{l}\text { Pesquisa documental; } \\
\text { Análise documental. }\end{array}$ & 2014 \\
\hline 11 & $\begin{array}{l}\text { Organização } \text { e representação do } \\
\text { conhecimento por meio de mapas } \\
\text { conceituais }\end{array}$ & Análise de conteúdo. & 2014 \\
\hline 12 & $\begin{array}{l}\text { Saúde coletiva: organização e } \\
\text { representação da informação sob a } \\
\text { perspectiva das palavras-chave de } \\
\text { artigos de periódicos científicos e a } \\
\text { formação acadêmica de seus autores }\end{array}$ & $\begin{array}{l}\text { Pesquisa documental; } \\
\text { Análise de palavras chaves } \\
\text { (técnica não especificada). }\end{array}$ & 2014 \\
\hline 13 & $\begin{array}{l}\text { Uso da oralidade na mediatização dos } \\
\text { websites de bibliotecas públicas }\end{array}$ & $\begin{array}{l}\text { Pesquisa documental; } \\
\text { Análise documental. }\end{array}$ & 2014 \\
\hline 14 & $\begin{array}{l}\text { A colaboração científica no Brasil nos } \\
\text { periódicos com Qualis A1 da Ciência da } \\
\text { Informação }\end{array}$ & $\begin{array}{l}\text { Análise de Redes Sociais } \\
\text { (ARS). }\end{array}$ & 2015 \\
\hline 15 & $\begin{array}{l}\text { A organização da informação em } \\
\text { prontuário eletrônico do paciente na } \\
\text { perspectiva das recomendações } \\
\text { usabilidade }\end{array}$ & $\begin{array}{l}\text { Método dedutivo de } \\
\text { delineamento documental. }\end{array}$ & 2015 \\
\hline 16 & $\begin{array}{ll}\begin{array}{l}\text { Comportamento informacional de } \\
\text { pacientes odontológicos }\end{array} & \\
\end{array}$ & $\begin{array}{l}\text { Entrevista (técnica do } \\
\text { incidente crítico). }\end{array}$ & 2015 \\
\hline 17 & $\begin{array}{l}\text { Habilidades informacionais dos } \\
\text { estudantes de artes visuais multimídia: } \\
\text { uma abordagem da competência em } \\
\text { informação e competência digital }\end{array}$ & $\begin{array}{l}\text { Pesquisa colaborativa; } \\
\text { Observação e diário de } \\
\text { pesquisa. }\end{array}$ & 2015 \\
\hline 18 & $\begin{array}{l}\text { Interfaces como metacomunicação: a } \\
\text { contribuição da engenharia semiótica } \\
\text { na representação no ciberespaço }\end{array}$ & $\begin{array}{l}\text { Análise documental; } \\
\text { Análise categorial }\end{array}$ & 2015 \\
\hline 19 & $\begin{array}{l}\text { Materialidade da informação no } \\
\text { contexto dos ambientes informacionais } \\
\text { digitais e os impactos na Arquivologia } \\
\text { nas conjunturas da preservação digital }\end{array}$ & $\begin{array}{l}\text { Pesquisa bibliográfica; } \\
\text { Gestão de conteúdos } \\
\text { empresariais. }\end{array}$ & 2015 \\
\hline 20 & $\begin{array}{l}\text { Mediação pedagógica e mediação da } \\
\text { informação no curso de Biblioteca } \\
\text { inclusiva, modalidade EAD }\end{array}$ & Análise do discurso. & 2015 \\
\hline 21 & $\begin{array}{l}\text { Memória do Sistema Municipal de } \\
\text { Bibliotecas Públicas de Londrina }\end{array}$ & $\begin{array}{l}\text { Entrevista por meio da } \\
\text { questão gerativa de narrativa; } \\
\text { Análise documental. }\end{array}$ & 2015 \\
\hline 22 & $\begin{array}{l}\text { Motor de busca aberto como estratégia } \\
\text { de indexação e mineração de dados }\end{array}$ & $\begin{array}{l}\text { Pesquisa bibliográfica; } \\
\text { Análise temática. }\end{array}$ & 2015 \\
\hline 23 & $\begin{array}{l}\text { O capital social e o compartilhamento de } \\
\text { informação jurídica: um estudo na } \\
\text { mídia social Facebook }\end{array}$ & $\begin{array}{l}\text { Pesquisa documental; } \\
\text { Questionário e formulário. }\end{array}$ & 2015 \\
\hline
\end{tabular}




\begin{tabular}{|c|l|l|l|}
24 & $\begin{array}{l}\text { O comportamento informacional de } \\
\text { advogados trabalhistas com os autos } \\
\text { digitais }\end{array}$ & $\begin{array}{l}\text { Entrevistas } \\
\text { Análise de conteúdo. }\end{array}$ & 2015 \\
\hline 25 & $\begin{array}{l}\text { O documento fotográfico na } \\
\text { organização do conhecimento: o } \\
\text { processo de transcodificação na } \\
\text { classificação arquivística }\end{array}$ & $\begin{array}{l}\text { Pesquisa bibliográfica; } \\
\text { Análise de conteúdo. }\end{array}$ & 2015 \\
\hline 26 & $\begin{array}{l}\text { O grupo Temma e a organização da } \\
\text { informação no âmbito do ENANCIB }\end{array}$ & $\begin{array}{l}\text { Pesquisa bibliográfica e } \\
\text { documental; } \\
\text { Análise documentária de } \\
\text { conteúdo. }\end{array}$ & 2015 \\
\hline 27 & $\begin{array}{l}\text { Práticas de pesquisa na pós-graduação: } \\
\text { um estudo das habilidades para a busca } \\
\text { de informação }\end{array}$ & $\begin{array}{l}\text { Análise de dados (técnica não } \\
\text { especificada). }\end{array}$ & 2015 \\
\hline 28 & $\begin{array}{l}\text { Tecnologias para aplicação da web } \\
\text { semântica nas unidades de informação }\end{array}$ & $\begin{array}{l}\text { Pesquisa bibliográfica e } \\
\text { documental; } \\
\text { Estudo de caso; } \\
\text { Análise de conteúdo }\end{array}$ & 2015 \\
\hline
\end{tabular}

Fonte: Resultados da Pesquisa.

Considerando que o objetivo desta pesquisa envolve apenas procedimentos de análise de dados, não é necessário considerar as pesquisas bibliográfica, documental e colaborativa, bem como a observação, a entrevista, o questionário e o estudo de caso, pois tais delineamentos e técnicas são usados para os procedimentos da pesquisa e para coletar dados, não para analisá-los.

Percebe-se que a análise de conteúdo é adotada em apenas seis trabalhos, nos índices 7, 11, 24, 25, 26 e 28. Pode-se incluir os índices 4, 18 e 22, visto que: análise categorial é uma das técnicas que pertence ao conjunto "análise de conteúdo"; que análise temática é uma espécie de análise categorial; e que análise de assunto equivale, em sua essência, à análise temática. Nove das dissertações, portanto, aplicaram a análise de conteúdo.

Por outro lado, alguns artigos não especificaram expressamente, no resumo ou na metodologia, a técnica de análise de dados. Isso aconteceu, por exemplo, no índice 27, que, apesar de explicar como a análise foi feita, não identificou qual técnica estava sendo empregada. Ademais, alguns dos que declararam uma técnica, não explicaram como ela é definida na literatura, como no índice 12 , que declarou a análise de palavras-chave sem apresentar referência alguma. Tais artigos foram contados como "técnica não especificada". Assim, com os ajustes mencionados, segue, no Quadro 2, a contagem de técnicas de análise de dados adotadas.

Quadro 2: Contagem das técnicas de análise de dados.

\begin{tabular}{|l|c|}
\hline \multicolumn{1}{|c|}{ Técnica } & Ocorrências \\
\hline Análise bibliométrica & 01 \\
\hline Análise de conteúdo & 09 \\
\hline Análise de discurso & 01 \\
\hline Análise de domínio & 01 \\
\hline Análise de redes sociais & 02 \\
\hline Análise documental & 09 \\
\hline Técnica não especificada & 07 \\
\hline
\end{tabular}

Fonte: Resultados da pesquisa.

Calculando-se o percentual entre o número de ocorrências de cada técnica e o número total de técnicas de análise de dados empregadas, é possível obter a 
disposição centesimal das técnicas. 0 resultado do cálculo está representado no Gráfico 1.

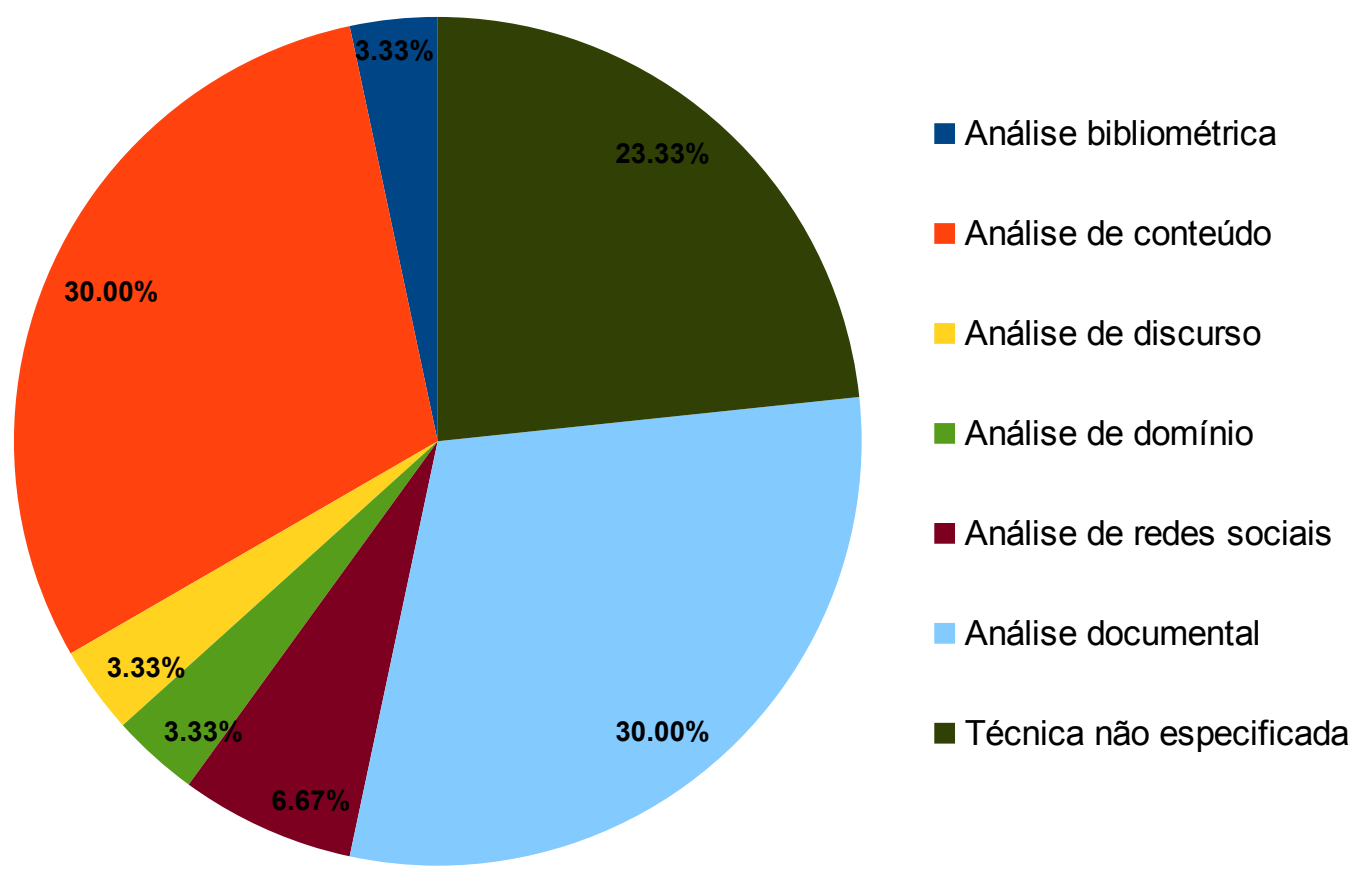

Gráfico 1: Disposição centesimal do emprego de cada técnica Fonte: Resultados da pesquisa.

Conforme o Gráfico 1, a análise de conteúdo e a análise documental foram as técnicas mais utilizadas, ambas com nove ocorrências. Juntas, as duas técnicas representam $60,00 \%$ de todo o espectro, ou seja, quase dois terços das técnicas de análise empregadas.

Esse resultado corrobora com White e Marsh (2006), em um artigo que listou trabalhos de CI publicados entre 1991 e 2005, quando elas concluíram que a AC é altamente flexível, tendo sido amplamente usada em estudos da Ciência da Informação com diversos objetivos.

Destaca-se, também, que $23,33 \%$ do gráfico é composto por técnicas não especificadas. Isso demonstra um descuido no modo como as metodologias foram redigidas nessas pesquisas, pois, se o pesquisador está utilizando um procedimento reconhecido pela comunidade científica, é importante que o especifique e o descreva com as devidas referências. Caso, entretanto, esteja aplicando um método novo, é apropriado que essa inovação seja, expressamente, declarada como tal.

\section{SÍNTESE DAS DISSERTAÇõES QUE APLICARAM A ANÁLISE DE CONTEÚDO}

Percebendo a quantidade de vezes que a análise de conteúdo foi empregada, passa a ser relevante investigar como ela foi utilizada. O Quadro 3 apresenta as nove dissertações que adotaram a técnica em questão, destacando o ano de sua defesa e a qual linha de pesquisa do PPGCI/UEL pertencem: Organização e Representação da Informação e do Conhecimento (1) e Compartilhamento da Informação e do Conhecimento (2). 
Quadro 3: Sumário das dissertações analisadas.

\begin{tabular}{|c|l|c|c|}
\hline $\begin{array}{c}\text { Índic } \\
\text { e }\end{array}$ & \multicolumn{1}{|c|}{ Título da Dissertação } & Ano & Linha \\
\hline 1 & $\begin{array}{l}\text { A representação temática da informação na saúde } \\
\text { coletiva: tendências temáticas dos trabalhos } \\
\text { desenvolvidos pelo programa de pós-graduação da } \\
\text { Universidade Estadual de Londrina }\end{array}$ & 2014 & 1 \\
\hline 2 & $\begin{array}{l}\text { Comportamento Informacional de pais de crianças } \\
\text { com Síndrome de Down }\end{array}$ & 2014 & 2 \\
\hline 3 & $\begin{array}{l}\text { Interfaces como metacomunicação: a contribuição } \\
\text { da engenharia semiótica na representação no } \\
\text { ciberespaço }\end{array}$ & 2015 & 1 \\
\hline 4 & $\begin{array}{l}\text { Motor de busca aberto como estratégia de indexação } \\
\text { e mineração de dados }\end{array}$ & 2015 & 1 \\
\hline 5 & $\begin{array}{l}\text { O comportamento informacional de advogados } \\
\text { trabalhistas com os autos digitais }\end{array}$ & 2015 & 1 \\
\hline 6 & $\begin{array}{l}\text { 0 documento fotográfico na organização do } \\
\text { conhecimento: o processo de transcodificação na } \\
\text { classificação arquivística }\end{array}$ & 2015 & 1 \\
\hline 7 & $\begin{array}{l}\text { O grupo Temma e a organização da informação no } \\
\text { âmbito do ENANCIB }\end{array}$ & 2015 \\
\hline 8 & $\begin{array}{l}\text { Organização e representação do conhecimento por } \\
\text { meio de mapas conceituais }\end{array}$ & $\begin{array}{l}\text { Tecnologias para aplicação da web semântica nas } \\
\text { unidades de informação }\end{array}$ & 2015 \\
\hline a pasquisa & 1 \\
\hline
\end{tabular}

Fonte: Resultados da pesquisa.

Pode-se observar no Quadro 3 que a técnica análise de conteúdo foi usada em dissertações com temáticas variadas e com diferentes locus de coleta de dados, evidenciando as diversas possibilidades de aplicação dessa técnica. Isso corrobora com Bardin (2011), segundo a qual a análise de conteúdo é marcada por uma grande disparidade de formas e adaptável a um campo de aplicação muito vasto, que inclui qualquer tipo de comunicação.

Segundo Souza e Stumpf (2009, p.52), "as linhas de pesquisa aglutinam as investigações que tem afinidades entre si, e a elas se filiam os projetos de pesquisa dos docentes e, consequentemente, as dissertações que orientam". 0 volume de dissertações concluídas segundo as linhas de pesquisa também pode ser visualizado no quadro 3, mas o que chama a atenção é que ela foi usada quase na totalidade na linha de pesquisa 1, referente à organização e representação da informação e do conhecimento.

Com o sumário das dissertações e as considerações preliminares sobre a linha de pesquisa concluídos, é possível proceder para as sínteses e observar como a análise de conteúdo foi empregada.

A dissertação, A representação temática da informação na saúde coletiva: tendências temáticas dos trabalhos desenvolvidos pelo Programa de Pós-Graduação da Universidade Estadual de Londrina, aborda a Saúde Coletiva, por meio de seus conteúdos temáticos, contribui, entre outros aspectos, com o estudo do processo social conhecido como saúde-doença, no âmbito coletivo e suas decorrentes propostas de ação. Entretanto, dada à expressiva gama de temas e enfoques que constituem o campo, evidencia-se a importância da organização destas informações para sua disseminação. Nesse sentido, recorreu-se aos aportes teóricos e metodológicos da Ciência da Informação, em especial, da representação da informação e, por intermédio do procedimento denominado Análise de Assunto, os termos que 
representam os assuntos e enfoques foram identificados nos resumos das dissertações e teses do Programa de Pós-Graduação stricto sensu em Saúde Coletiva da UEL. Outros aspectos analisados relacionam-se à formação acadêmica de seus autores e às linhas de pesquisa correlacionadas às temáticas dos trabalhos. Caracterizado como estudo qualitativo, de cunho descritivo, concretizado por meio de pesquisas bibliográficas e documentais. 0 corpus da pesquisa constituiu-se de 36 resumos de dissertações e teses. A partir da leitura dos resumos e palavras-chave foi realizada a seleção de conceitos e extração de termos e suas buscas nos Descritores de Ciências da Saúde (DeCS), para então proceder a análise temática para identificação dos assuntos dos trabalhos analisados.

Quanto a dissertação, Comportamento Informacional de pais de crianças com Síndrome de Down, teve como objeto de investigação o comportamento informacional de pais de crianças com Síndrome de Down. Foram analisados as necessidades, a busca e o uso da informação em diferentes contextos, considerando-se a abordagem cognitiva, os aspectos de acesso à informação e do significado cultural atribuído pelos participantes às pessoas com deficiência, decorrentes das influências ideológicas e sociais. 0 estudo foi de natureza exploratória e qualitativa. A amostra foi delineada com base nos prontuários do Instituto Londrinense de Educação para Crianças Excepcionais (ILECE), composta por dois grupos de pais de filhos com Síndrome de Down, crianças nascidas nas décadas de 1960 a 1980 e outro grupo com crianças nascidas nos anos de 2009 a 2013. Foram usados como instrumentos de coleta de dados formulário para a pesquisa documental e entrevista semiestruturada. Utilizou-se a técnica de análise de conteúdo para tratamento dos dados coletados nas entrevistas. A análise foi feita por meio da transcrição completa das entrevistas, a categorização das respostas com base no objetivo de identificar o comportamento informacional dos entrevistados. A categorização permitiu a construção de quadros e a realização de inferências.

Na terceira, Interfaces como metacomunicação: a contribuição da engenharia semiótica na representação no ciberespaço apresenta-se as Interfaces como Metacomunicação do designer no ciberespaço, identificando a contribuição da Engenharia Semiótica no processo de significação e representação. Para efetuar a Análise Documental, utilizou-se a técnica de análise categorial, ou seja, um desmembramento dos signos em categorias orientadas pela semiótica peirciana, sendo: os Ícones/Hipoícones, Índices e Símbolos; e também pelas categorias elencadas pela Teoria da Engenharia Semiótica: Signos Estáticos, Dinâmicos e Metalinguísticos. Analisou o uso destes para uma metacomunicação do designer para o sujeito informacional que navega no site da Biblioteca Nacional da Austrália e da Biblioteca do Congresso dos Estados Unidos.

A quarta dissertação, Motor de busca aberto como estratégia de indexação e mineração de dados teve como objetivo analisar o motor de busca, baseado em software livre YaCy/Solr como estratégia de indexação e mineração de dados. Foi utilizada pesquisa qualitativa, exploratória, bibliográfica e aplicada com a técnica de análise temática. Para que fosse alcançado o objetivo de evidenciar as capacidades de mineração de dados nos motores abertos de busca, o estudo fez uso, como base de análise, do banco de dados da Revista Informação \& Informação da Universidade Estadual de Londrina. 0 autor declarou que usou a técnica de análise temática, no entanto não explicou como ela foi aplicada. Ao ler o trabalho, foi possível observar que ele apresentou um relatório de seu experimento com o motor de busca e efetuou inferências sobre seus relatos. Não foram constatadas, portanto, a identificação e a categorização temática dos elementos básicos de análise. 
0 objetivo da quinta dissertação, $O$ comportamento informacional de advogados trabalhistas com os autos digitais, foi analisar o comportamento informacional dos advogados trabalhistas da região de Londrina na elaboração das peças judiciais, utilizando o processo judicial eletrônico (PJe), com foco na transição do processo físico para o eletrônico. Utilizou-se a entrevista semiestruturada para coletar os dados, com uma amostragem composta por dez advogados que atuam na área trabalhista e usam os sistemas de autos digitais disponíveis no Estado, o Escritório Digital do Tribunal Regional do Trabalho (TRT-PR) e o PJe nacional. Os dados foram tratados utilizando-se a técnica de análise de conteúdo. Com base no instrumento de coleta e nas respostas, o autor categorizou diversos elementos e mediu suas frequências. As inferências foram reveladas durante a apresentação dos resultados da análise.

o documento fotográfico na organização do conhecimento: o processo de transcodificação na classificação arquivística é o título da sexta dissertação que buscou questionar como se dá o processo da transcodificação do documento fotográfico na organização do conhecimento, em especial na classificação arquivística. Como objetivo principal pesquisou o processo da transcodificação para a classificação do documento fotográfico, assim como verificou o processo, elencou os elementos para a classificação arquivística e categorizou os elementos a luz da análise de conteúdo. A autora partiu da hipótese de que a identificação da imagem pelo usuário se dá por aspectos estéticos, não pelos caminhos da Ciência da Informação. Seu experimento foi realizado na mídia social Facebook, onde se coletou comentários aleatórios de internautas. Ela identificou os elementos a serem analisados, elaborou indicadores e, com base neles, interpretou os dados.

A sétima dissertação, $O$ Grupo Temma e a organização da informação no âmbito do ENANCIB teve como objetivo explorar a diversidade de pesquisas desenvolvidas pelos membros do Grupo, bem como apresentar fundamentação teórica e metodológica da Organização da Informação com base nos diferentes enfoques temáticos e concepções do Grupo no âmbito GT2 do ENANCIB. Por meio de resumos e palavras-chave buscou identificar as temáticas presentes nos estudos do Grupo TEMMA, no contexto no GT mencionado. Nesse sentido, para que os objetivos propostos pudessem ser realizados, utilizou como corpus da pesquisa o principal evento científico da Ciência da Informação: o ENANCIB, considerando o período de 1994 a 2014. Dessa forma, como percurso metodológico para a coleta de dados, o autor utilizou como locus o Repositório "Questões em Rede" e, para a análise dos trabalhos coletados utilizou o procedimento de análise documentária de conteúdo. Ao todo foram coletados 83 artigos dos 18 membros do Grupo. Em seguida, foi realizada a análise dos resumos e palavras-chave dos trabalhos, por meio da leitura técnica e identificação dos conceitos que representavam os assuntos abordados em cada trabalho.

O objetivo geral da Organização e representação do conhecimento por meio de mapas conceituais, oitava dissertação, foi desenvolver um estudo teórico-metodológico para a aplicação dos Mapas Conceituais no processo de análise - síntese representação para aprimorar a Organização e Representação do Conhecimento, pelo fato de ser um exercício intelectual. Quanto aos procedimentos metodológicos, caracterizou-se como exploratório e descritivo com abordagem qualitativa, utilizando o método análise de conteúdo. 0 universo da pesquisa constituiu-se em um estudo teórico-metodológico entre os anos de 2003 a 2013, em periódicos científicos eletrônicos nacionais, dos quais foram selecionados 18 periódicos e 11 produções científicas dos ENANCIBs. Para a coleta de dados, utilizou-se da estratégia de busca por meio da palavra-chave mapa conceitual no singular e no plural, nos idiomas 
português, espanhol e inglês. A autora constituiu corpus do trabalho (já mencionado), identificou elementos para a unidade de registro, realizou a categorização (gerando uma lista de conceitos para atribuição aos mapas conceituais) e efetuou suas inferências com base nas perguntas "por quê", "como", "para que" e "para quem", bem como interpretou suas ilações em cada categoria.

A última dissertação, isto é a nona, foi Tecnologias para aplicação da web semântica nas unidades de informação. Este estudo descreveu as tecnologias, recomendações e padrões necessários para a aplicação da Web Semântica nas unidades de informação. Realizou uma abordagem qualitativa como proposta metodológica, que permitiu uma percepção minuciosa das características do objeto de pesquisa. As técnicas adotadas foram os estudos bibliográficos e documentais, aliadas à metodologia de estudo de caso e análise de conteúdo, que proporcionou uma percepção mais precisa das tecnologias que abrangem o projeto da Web Semântica, sendo analisado o site da Biblioteca Virtual Europeana. Para a realização da investigação do estudo de caso organizou-se em cinco categorias que tornaram-se itens elementares da pesquisa durante todo o processo de análise de resultados. Elaborou-se um framework com o propósito de representar o processo de estabelecimento da Web Semântica nas unidades de informação. A elaboração do framework com as cinco categorias, ou seja, o fato de ter sido realizada uma categorização foi o que levou o autor a declarar que empregou a análise de conteúdo, no entanto, ao ler a dissertação, não fica evidente a aplicação da técnica.

\section{CONSIDERAÇÕES FINAIS}

As pesquisas analisadas distinguiram-se quanto ao tipo de coleta de dados e quanto às etapas de análise de resultado. Adotaram-se para a coleta de dados pesquisas bibliográfica, documental e colaborativa, bem como a observação, a entrevista, o questionário e o estudo de caso. Quanto à análise dos resultados, cada trabalho relacionou a categorizarão da fala dos autores com a fundamentação teórica levantada. A organização dos resultados nos diferentes casos derivou na construção do significado do discurso reordenado pelo pesquisador.

As temáticas abordadas na produção refletem as características da área de concentração e de suas linhas de pesquisa. Com base no Quadro 1 e no Gráfico 1, entende-se que a análise de conteúdo foi uma das técnicas mais empregadas, com a frequência de aplicação de 30,00\%, enquanto a outra foi a análise documental, com a mesma porcentagem. As demais, juntas, somaram 40,00\%. Acredita-se que o resultado se deve à versatilidade do método, que, conforme foi explicado no referencial teórico, pode ser aplicado em diversas áreas do conhecimento. Ademais, o fato de o método consistir em um conjunto de técnicas também contribui para os resultados, visto que três das dissertações analisadas não declaravam, expressamente, o uso da análise de conteúdo, mas de técnicas que fazem parte do conjunto.

Como observado nas dissertações que utilizaram o método, não existe um esquema rígido de utilização. A análise do método de operacionalização das dissertações demonstrou a peculiaridade de cada trabalho e a influência determinante da sensibilidade e percepção do pesquisador na reconstrução do significado embutido nos discursos coletados. Entretanto, foram constatados casos em que a aplicação da técnica não foi explicada com clareza e, até mesmo, um caso em que, apesar de seu emprego ter sido declarado, ele não foi executado.

Enfim, acredita-se que não exista uma análise superior ou inferior, o importante é que o pesquisador conheça as várias formas de análise existentes e saiba as suas diferenças, o que permite uma escolha consciente do referencial 
teórico-analítico, decorrente do tipo de análise que irá empregar na pesquisa, fazendo sua opção com responsabilidade e conhecimento. Somando-se a isso, ressalta-se também a relevância de se elaborar com clareza e de forma detalhada a descrição dos procedimentos adotados nas pesquisadas de dissertações.

\section{REFERÊNCIAS}

BARDIN, L. Análise de conteúdo. São Paulo: Edições 70, 2011.

GODOY, A. S. Pesquisa qualitativa: tipos fundamentais. Revista de Administração de Empresas, São Paulo, v. 35, n. 3, p. 20-29, maio/jun. 1995.

LASSWELL, H.D. Propaganda Technique In World War I. 2010. Disponível em: $<$ https://mitpress.mit.edu/books/propaganda-technique-world-war-i $>$. Acesso em: 20 fev. 2017.

LIMA, J. L. O.; MANINI, M. P. Metodologia para análise de conteúdo qualitativa integrada à técnica de mapas mentais com o uso dos softwares NVIVO e FREEMIND. Informação \& Informação, Londrina, v. 21, n. 3, p. 63-100, set./dez. 2016. Disponível em: <http://www.uel.br/revistas/uel/index.php/informacao/article/view/23879>. Acesso em: 30 abr. 2017.

MARCONI, M. de A.; LAKATOS, E. M. Técnicas de pesquisa. 5 ed. São Paulo: Atlas, 2002.

MARCONI, M. de A.; LAKATOS, E. M. Fundamentos de metodologia científica. 7. ed São Paulo: Atlas, 2010.

POPPER, K. Lógica da pesquisa científica. 9. ed. São Paulo: Cultrix, 1993.

SOUZA, R. F.; STUMPF, I. R. C. Ciência da Informação como área do conhecimento: abordagem no contexto da pesquisa e da pós-graduação no Brasil. Perspectivas em Ciência da Informação, Belo Horizonte, v.14, número especial, p. 41-58, 2009. Disponível em: <http://www.scielo.br/pdf/pci/v14nspe/a04v14nspe.pdf>. Acesso em: 03 mar. 2017.

WHITE M. D.; MARSH E. E. Content analysis: a flexible methodology. 2006. Disponível em: $<$ https://www.ideals.illinois.edu/bitstream/handle/2142/3670/ResearchProcess.pdf?sequen $\mathrm{ce}=2>$. Acesso em: 28 abr. 2017.

WOIDA, L. M. Análise de conteúdo aplicada a uma pesquisa de cultura informacional. In: VALENTIM, M. L. P. (Org.). Ambientes e fluxos de informação. 17.ed. São Paulo: Cultura Acadêmica, 2010. 